\title{
Mid Trimester Termination of Pregnancy : Role of Combined Mifepristone and Misoprostol
}

Farah Naz Mabud ${ }^{1 *}$

Tahera Begum ${ }^{1}$

Alok Nandy ${ }^{2}$

Serajun Noor ${ }^{1}$

'Department of Obstetrics \& Gynecology Chattogram Maa-O-Shishu Hospital Medical College Chattogram, Bangladesh.

'Department of Anesthesia and Critical Care Chattogram Maa-O-Shishu Hospital Medical College Chattogram, Bangladesh.
*Correspondence to:

\section{Dr. Farah Naz Mabud}

Assistant Professor

Department of Obstetrics \& Gynecology

Chattogram Maa-O-Shishu Hospital Medical College Chattogram, Bangladesh.

Mobile: +8801678221144

Email: farah.naz.mabud@gmail.com

Date of Submission : 10.11 .2019

Date of Acceptance : 20.12 .2019

www.banglajol.info/index.php/CMOSHMCJ

\begin{abstract}
Background: Mid trimester abortions constitute 10\%-15\% of all induced abortions world wide. Over the last decade this increase is due to better prenatal screening. It can be done by surgical and medical methods. Medical methods such as Misoprostol is widely used for mid trimester abortion. Mifepristone has antiprogesterone property, so addition of Mifepristone with Misoprostol can increase its effectiveness. To assess the safety, effectiveness and acceptibility of combined Mifepristone and Misoprostol for mid trimester medical termination of pregnancy (Between 13-24 weeks of gestation).
\end{abstract}

Materials and methods: This experimental study was conducted among 40 healthy women who presented for mid trimester termination of pregnancy between 13-24 weeks with missed abortion, gross congenital anomalies with or without previous history of one caesarian section. The study was conducted from March October 2018 at Chattogram Maa-O-Shishu Hospital Medical College, Chattogram, Bangladesh. Each woman received a single dose of tablet Mifepristone 200mg. After 24 hours, 200 mcg vaginal Misoprostol was administered which was repeated at 6 hourly interval for maximum of 5 doses $(1000 \mathrm{mcg})$ in 24 hours. Success was taken as complete expulsion of fetus and placenta within 24 hours of first dose of Misoprostol. Primary and secondary outcomes were measured. Statistical analysis was done using SPSS version 23.

Results: Success rate of complete abortion was 97.5\%. Mean Induction Abortion Interval was11.59 hours (SD \pm 3.34). Mean dose of Misoprostol was 1.85 (SD \pm 0.77 ) or $370 \mathrm{mcg}$. Over all safety of the study was satisfactory with only 1 patient experienced fever and 1 had nausea.There was no major complication.

Conclusion: The Mifepristone/Misoprostol regimen is a highly effective as well as safe option for mid trimester medical termination of pregnancy with a short induction abortion interval and it can also be used in scarred uterus with close supervision.

Key words: Mifepristone; Misoprostol; Mid trimester abortion; Medical termination of pregnancy.

\section{INTRODUCTION}

Mid trimester abortion constitutes $10 \% 15 \%$ of all abortion but are responsible for two-third of all major complications (WHO 1997) ${ }^{1}$.

There has been a gradual increase in the second trimester termination of pregnancy because of the widespread introduction of prenatal screening programs which detects serious fetal anomalies ${ }^{2}$.

Various surgical and medical methods have been tried for the second trimester MTP with varying success and induction abortion interval. During the last decade medical 
methods for second trimester induced abortions have been considerably improved. According to the WHO and Royal College of Obstetrics and Gynaecologists Mifepristone followed by Misoprostol is considered as an effective and safe method for second trimester abortions ${ }^{3,4}$. Prostaglandin (PGE1,PGE2 and PGF2alpha) has been used for mid trimester pregnancy termination in the last 20 years. When prostaglandin E1 analogue (Gameprost or misoprostol) are used alone for second trimester MTP, the mean Induction Abortion Interval (IAI) can be as long as $12-16$ hours $^{2,5}$. Mifepristone (RU486 a substitute 19-norethisterone derivative) acts by blocking progesterone receptors. Progesterone is a key hormone in maintaining pregnancy by keeping the uterus in a quiescent state. It prevents softening and dilatation of the cervix, reduces prostaglandin output from the deciduas and suppresses uterine contractions. So, pre treatment with antiprogesterone (Mifepristone) prior to prostaglandin administration acts by blocking progesterone receptors results in vascular damage, decidual necrosis and bleeding which leads to cervical softening, increased uterine sensitivity to PG and conversion of the quiet pregnant uterus into an open organ of spontaneous activity $^{6}$. It leads to reduction in IAI, the total dose of prostaglandins required as well as the analgesia requirement ${ }^{5,7}$. The combination of Mifepristone and Misoprostol has been found safe and effective for mid trimester termination of pregnancy in various studies ${ }^{4,8}$.

The present study was conducted to assess the effectiveness of combination of Mifepristone followed by successive doses of vaginal misoprostol for mid trimester abortions and to study any side effects of the above regimen.

\section{METHODS AND MATERIALS}

This prospective study was done in Chattagram Maa-O-Shishu Hospital Medical College from March October 2018. A total of 48 patients presented to us for termination of pregnancy between 13-24 weeks period of gestation. 40 eligible patients were included in the study after taking written informed consent and proper counseling in accordance with the inclusion criteria Ethical approval was taken from the ethical committee of the institute.

\section{Inclusion criteria}

i) All patients admitted in the labour ward seeking for medical termination for missed abortion or major congenital anomalies

ii) Patients with history of 1 caesarian section were also included in the study.

Exclusion criteria

i) Women who were hemodynamically unstable at the time of presentation

ii) Women who had either taken MTP pill from outside or selfprescribed, came with inevitable or incomplete abortion

iii) Women with known case of heart disease, uncontrolled hypertension, bronchial asthma or coagulation disorder, on anti coagulant or corticosteroid therapy

iv) Haemoglobin $<8 \mathrm{gm} \%$

v) $>1$ caesarian section.
All women were given tab Mifepristone (200 mg) to be swallowed under supervision .After 24 hours, tab Misoprostol (200 mcg) was administered per vaginum in the posterior fornix which was repeated at 6 hourly intervals for maximum 5 doses $(1000 \mathrm{mcg})$ for 24 hours depending on cervical dilatation, uterine contraction and history of previous scar. Sterile vulval pads were given which were examined at regular intervals. Onset of uterine contractions, vaginal bleeding and passage of any product of conceptions and placental completeness were monitored. The time of expulsion of fetus and placenta was noted. When placenta was not expelled spontaneously, evacuation and curettage was done. Successful termination was considered as the occurrance of complete abortion within 24 hours of first dose of Misoprostol.

Following Primary Outcomes were Measured:-

i) Rate of complete abortion after initial Misoprostol administration

ii) Induction abortion interval (IAI) calculated from the time of first dose of Misoprostol administration to complete expulsion of fetus and placenta

iii) Mean dose of Misoprostol required.

Secondary Outcomes were:-

i) Side effects like nausea/ vomiting. diarrhoea, fever, headache

ii) Any complications observed with the regimen like excessive bleeding, incomplete abortion, need for blood transfusion, sepsis, scar rupture or uterine injury.

\section{RESULTS}

A total of 48 women underwent mid trimester pregnancy termination during the study period. Out of these, 4 patients came with inevitable abortion, 2 had self administered abortion pills and 2 were with previous history of 2 caesarian section so they were excluded from the study. Finally 40 cases were included in the study and analysed.

The mean age of the women included in the study was 23 years with a range of $18-32$ years. $32.5 \%$ of total patients were nullipara, $22.5 \%$ were Primigravida and remaining $45 \%$ were multipara. $17.5 \%$ women presented in $13-16$ weeks, $55 \%$ were in $17-20$ weeks and $27.5 \%$ of women were in $21-24$ weeks of gestation. $32.50 \%$ women came with previous history of abortion. 3 women came with previous caesarian section and 3 women came for MTP for congenital malformations eg. neural tube defect.

Table1: Demographic profile of mothers $(n=40)$

$\begin{array}{lcc}\text { Particular } & \text { Frequency }(\mathrm{n}) & \text { Percentage }(\%) \\ \text { Age (Years): } & & \\ \text { 1. } \quad<19 \text { years } & 03 & 7.50 \% \\ \text { 2. 19-24 years } & 22 & 55.00 \% \\ \text { 3. 25-29 years } & 11 & 27.50 \% \\ \text { 4. >29 years } & 04 & 10.00 \% \\ \text { Parity: } & & \\ \text { 1. } \quad 0 & 13 & 32.50 \% \\ \text { 2. } 1 & 9 & 22.50 \% \\ \text { 3. }>=2 & 18 & 45.00 \%\end{array}$




$\begin{array}{lcc}\begin{array}{l}\text { Previous history of C/S } \\ \text { Previous history of } \\ \text { Termination of }\end{array} & 3 & 7.50 \% \\ \begin{array}{l}\text { Pregnancy (TOP) } \\ \text { Gestational age: }\end{array} & 13 & 32.50 \% \\ \text { 13-16 Weeks } & 07 & 17.50 \% \\ 17-20 \text { Weeks } & 22 & 55.00 \% \\ 21-24 \text { Weeks } & 11 & 27.50 \%\end{array}$

Mean total dose of Misoprostol was calculated to be $370 \mathrm{mcg}$ (95\% CI 320.77-419.22) Table 2. Mean Number of doses of Misoprostol required was found to be $1.85(95 \%$ CI $1.60-2.09)$. Mean Induction abortion interval was 11.59 hours $(95 \% \mathrm{CI}$ 22.58-25.01 ) Table 2 .

Table 2 : Details of MTP procedure $(n=40)$

\begin{tabular}{lrr} 
& Mean & \multicolumn{1}{c}{$\mathbf{9 5 \%}$ CI } \\
No. of Dose of Misoprostol & 1.85 & $1.60-2.09$ \\
Dose of Misoprostol & 370 & $320.77-419.22$ \\
Interval of Abortion & 11.59 & $10.53-12.66$ \\
\hline
\end{tabular}

Table 3 : Distribution of subgroups of induction abortion interval $(n=40)$

\begin{tabular}{lccc} 
Interval Group & Frequency (n) & Percentage (\%) & $\begin{array}{l}\text { Cumulative } \\
\text { Percentage (\%) }\end{array}$ \\
\hline 00-06 Hours & 02 & 05.13 & 05.13 \\
07-12 Hours & 18 & 46.15 & 51.28 \\
13-18 Hours & 18 & 46.15 & 97.44 \\
19-24 Hours & 01 & 02.56 & 100.00 \\
\hline
\end{tabular}

$5.13 \%(\mathrm{n}=2)$ women had complete abortion with in 6 hours, $46.15 \%(\mathrm{n}=18)$ within $7-12$ hours

$46.15 \%(n=18)$ within $13-18$ hours and rest of the $2.56 \%(n=1)$ women had complete abortion within 19-24 hours.

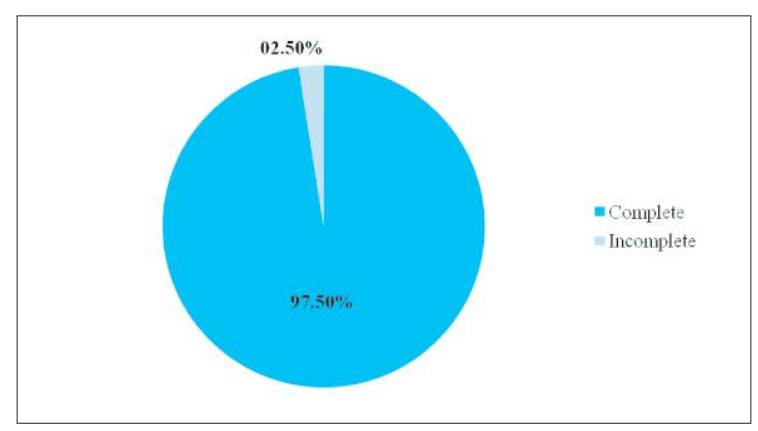

Figure 1: Distribution of abortion $(n=40)$

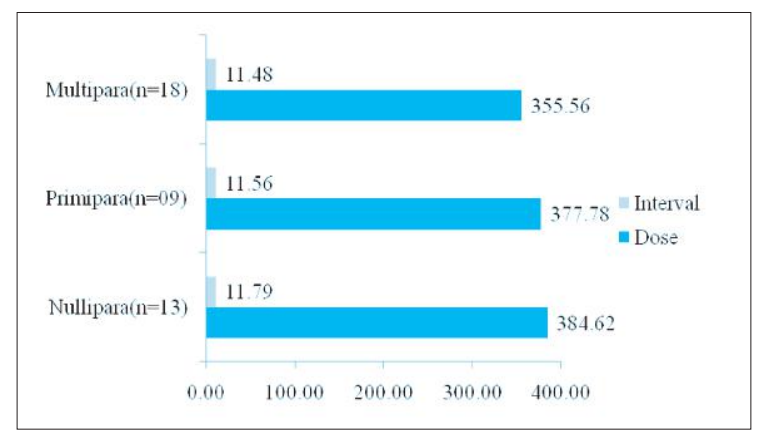

Figure 2: Dose and induction abortion interval in relation to parity
Nullipara ( $n=13$ ) Primipara ( $n=9)$ Multipara $(n=18)$

Successful complete abortion (Expulsion of fetus and placenta ) 24 hours after the instillation of first dose was found in 39 cases $(97.5 \%)$. However, evacuation was done in 1 case due to incomplete expulsion. There were 3 cases of previous history of 1 caesarian section. All of them were presented in 17-20 weeks of gestation. In these group of patients mean induction abortion interval was 10.83 hours. All of these patients had complete abortion and none required surgical intervention.

9 patients received injectable analgesics for moderate discomfort. 7 out of these were primigravida. Oral analgesics were sufficient for pain relief in 21 patients. There were 10 patients who did not require any analgesics.

Table 4 : Side effects $(n=40)$

\begin{tabular}{lcccc} 
& \multicolumn{2}{c}{ Yes } & \multicolumn{2}{c}{ No } \\
& $\begin{array}{r}\text { Frequency } \\
\text { (n) }\end{array}$ & $\begin{array}{c}\text { Percentage } \\
\text { (\%) }\end{array}$ & $\begin{array}{c}\text { Frequency } \\
\text { (n) }\end{array}$ & $\begin{array}{c}\text { Percentage } \\
(\%)\end{array}$ \\
Chill, Rigor & 0 & 0 & 40 & 100 \\
Fever & 1 & 2.5 & 39 & 97.5 \\
Nausea/ Vomiting & 1 & 2.5 & 39 & 97.5 \\
Ruptured Uterus & 0 & 0 & 40 & 100 \\
\hline
\end{tabular}

There was no major complications observed. Only 1 patient had fever and 1 patient had nausea. None had diarrhea or uterine rupture. There was no case of major obstetric haemorrhage observed during the study.

\section{DISCUSSION}

Mid trimester MTP is a difficult situation owing to the prolonged time required for the abortion process and associated complications. In developing countries especially rural areas second trimester MTP is a real challenge owing to the limited resources available. In earlier days surgical methods used be the standard method for mid trimester MTP. In the last 20 years there is emergence of medical methods for mid trimester pregnancy termination consisting of prostaglandins alone or in combination with anti-progesterone Mifepristone. Still a method which is $100 \%$ reliable, safe and affordable is not known.

Misoprostol as an effective abortificient is being successfully used through all routes ie sublingual, oral, vaginal and in different regimens with varying induction abortion interval. Combination of Mifepristone and Misoprostol with different dose schedules is widely used method for $2^{\text {nd }}$ trimester MTP. Priming of the uterus with Mifepristone makes it more sensitive to prostaglandin. It binds with the progesterone receptors and antagonizes the action of progesterone resulting in increase in prostaglandin production and decreased deactivation of prostaglandins. It also softens the cervix, thus enhancing the efficacy of prostaglandin.

We have given Misoprostol $200 \mathrm{mcg}$ vaginally 6 hourly for 5 doses 24 hours after priming with $200 \mathrm{mg}$ of oral Mifepristone. It has been seen that vaginal route of administration of Misoprostol is safer and more effective than oral route with less side effects due to better bioavailibility of the drug at the target site $^{9,10}$ 
We compared our study with other studies where Mifepristone $200 \mathrm{mg}$ followed by minor variations of subsequent dosages and routes of administration of Misoprostol. Various studies have shown higher success rate and reduced induction abortion interval and need for lesser dose of Misoprostol when Mifepristone is added to Misoprostol ${ }^{5,7,11}$. Gupta et al10 gave the second dose of Misoprostol vaginally or sublingually after 4-6 hours of first dose $^{12}$. The success rate was $91.42 \%$ compared to that of ours where the success rate is $97.5 \%$. Ashok et al used vaginal route for the first dose and oral for the subsequent doses of Misoprostol and the success rate was $97.1 \%$ which is very close to our success rate ${ }^{5}$.

In our study, minimum IAI is 5 hours 15 minutes ,maximum IAI is 19 hours and mean induction abortion interval is 11.59 hours which is very close to the another study performed by Maninder et al following the same regimen and the induction abortion interval was 11.26 hours $^{13}$. Some other studies like Ashok PW et al and Goh et al the induction abortion interval were 6.5 hours and 6.7 hours respectively though they followed different dose schedules and various routes of Misoprostol administration after $200 \mathrm{mg}$ of Mifepristone intake $\mathrm{e}^{5,14}$.

In our study mean number of dose of Misoprostol was found to be 1.85 and the total dose was calculated to be $370 \mathrm{mcg}$ which is also close to the study by Maninder et al the mean total number of dose was 2.13 and mean total dose was 610.42 $\mathrm{mcg}^{13}$. Our present study is also comparable to other studies ${ }^{5,13}$.

None of the patients in our study aborted completely with Mifepristone alone though studies have reported $0.2 \%-0.5 \%$ incidence of complete abortion with only Mifepristone ${ }^{5,8,12}$.
There were 3 patients in our study who had undergone caesarean section prior to present pregnancy. All of them had complete abortion with combination of Mifepristone and Misoprostol. Ther were various case reports showing uterine rupture in previously scarred uterus undergoing mid- trimester pregnancy termination ${ }^{15}$. Again many have shown safety of Mifepristone and Misoprostol for mid trimester MTP in cases of previous caesarian section ${ }^{16,17}$

In our study, there was no relation found between the parity and induction abortion interval which is consistent with the study performed by Gupta et $\mathrm{al}^{12}$.

There was no case of rupture uterus or need for hysterotomy. Nulliparous patients required more injectable analgesics as compared to the multiparous women which can be due to their low threshold for pain which also shows the similarity with the literature ${ }^{2,9}$.

\section{LIMITATION}

The limitations of the present study were its sample size and not using the randomization.

\section{CONCLUSION}

Use of mifepristone and misoprostol is highly effective and safe option for mid-trimester medical termination of pregnancy. It has shorter induction abortion interval, high success rate and less side effects with significantly short hospital stay. It can also be used in scarred uterus with caution. However, a broad based, well designed randomized study is hereby suggested for national policy formulation.

\section{DISCLOSURE}

All the authors declared no competing interest. 


\section{REFERENCES}

1. World Health Organization. Medical methods for Termination of Pregnancy. WHO Technical Report Series 871, World Health Organization, Geneva. 1997.

2. Hammond C.Recent advances in second trimester abortion:an evidence based review :Am J obstet Gynecol. 2009;200(4) : 347-356

3. Royal College of Obstetricians and Gynaecologists. The care of women requestinfg induced abortion. London: Royal College of Obstetricians and Gynaecologists. 2004.

4. World Health Organization. Unsafe Abortion : Global estimates of the incidence of unsafe abortion and associated mortality in 2004. 4 ed. Geneva: World Health Organization. 2004.

5. Ashok PW, Templeton A, Wagaarachchi PT, FlettGM. Midtrimester medical termination of pregnancy: A review of 1002 consecutive cases. Contraception. 2004;69(1):51-58.

6. Bygdeman M and Swahn ML. Progesterone receptor blockage effect on uterine contractility and early pregnancy. Contraception. 1985;32:45-51.

7. Nagaria T,Sirmor N. Misoprostol vs mifepristone and Misoprostol in second trimester termination of pregnancy. J Obstet Gynaecol India. 2011;61(6): 658-662.

8. Hammoda H,Ashok PW. Flett GM, Templeton A . A randomized trial of mifepristone in combination with Misopristol administered sublingually or vaginally for medical abortion at 13- 20 weeks gestation. Hum Reprod. 2005;20(8): 2348-2354.

11. Lalitkumar S, Bygdeman M,Gemzell Danielson K. Midtimester induced abortion: A review. Hum Reprod Update. 2007;13(1):37-52.

10. Gupta N, Mittal S. Is mifepristone needed for second trimester termination of pregnancy? J Turkish-German Gynecol Assoc. 2007;8(1):58-62.

13. Maninder K,Harpreet K, Shushmita S,Nishu M. Mifrpristone followed by Misoprostol for Mid trimester Abortion : A Prospective Study Indian Journal of Obstetrics and Gynaecology Research. 2015;2(4):227-231.

14. Goh SE,Thong KJ. Induction of second trimester abortion (12-20 weeks) with mifepristone and misoprostol: a review of 386 consecutive cases. Contraception. 2006; 73(5): 516-519 .

9. Ngai SW, Tang OS and Ho PC. Randomized comparison of vaginal ( $200 \mathrm{mcg}$ every 3 hourly) and oral (400mcg) every 3 hourly) Misoprostol when combined with mifepristone in termination of second trimester pregnancy. Hum Rep. 2000;15:2205-2208.

10. Tang OS, Chang CC, Kan AS and Ho PC. A prospective randomized comparison of sublingual and oral Misoprostol when combined with mifepristone for medical abortion at 12-20 weeks gestation. Hum Rep. 2005;20:3062-3066.

15. Chen M, Shih Je, Chiu W T,Hsieh FJ . Separation of caesarean scar during second trimester intravaginal Misoprostol abortion. Obstet Gynaecol. 1999;94:840.

16. Dickinson JE. Misoprostol for second trimester pregnancy termination in women with prior caesarean delivery. Obstet Gynaecol. 2005; 105:352-356.

17. Herabutya Y, Chanarchakul B and Punyavachira P. Induction of labour with vaginal Misoprostol for second trimester termination of pregnancy in the scarred uterus. Int J Gynaecol Obstet. 2003;83:293-297. 